\title{
Double drum root crop washer with chain transmission
}

\author{
N N Mirzaev ${ }^{1}$, M I Mamasalieva ${ }^{1}$ \\ ${ }^{1}$ Tashkent State Technical University named after Islam Karimov University street №2, Tashkent city; Uzbekistan \\ E-mail: gulchehra2767@mail.ru
}

\begin{abstract}
Annotation. The paper describes a two-drum root crop washer with a chain gear, which was designed by the authors of this work and assembled for testing and working in a mini technological line of root crop processing. The authors have calculated the chain gear specifically for this design.
\end{abstract}

\section{Introduction}

At the present time for washing food plant raw materials and sanitary treatment of equipment washing machines of various types and designs are used. They are classified as follows: by the nature of the process (continuous and intermittent); by the type of processed objects (for washing raw materials); by the type of devices which move the washed objects (linear and drum-type); by the method of exposure to cleaning medium (spritz, washed and washedspritz).

Of the variety of washing machines, the most widespread are blade, belt, drum, vibrating, combined, elevator, brush, etc.

The following requirements are made to the washing machines: high degree of cleanliness of washed objects, elimination of raw material damage or breakage and deformation of containers, minimum water, and energy consumption, easy manufacturing and maintenance, high operational reliability, small overall dimensions, and weight.

\section{Materials and research methods}

The choice of a washing machine is determined by the structural-mechanical and strength properties of the plant material, as well as by the type and amount of dirt on the surface of raw materials. Tumblast washing machines. Washing in the drum washers is made with the rotation of the drum through the intensive agitation of the raw materials and the impact of the falling raw materials on the surface of the water. The efficiency of the washing process is determined by the ratio of the forces acting on the raw material in the drum.

At a low number of drum revolutions, the raw material is located in its lower part. With the increase in the number of rotations of the drum, the lifting angle of the raw material increases (in smooth drums), and the higher the number of rotations, the higher the lift, detachment, and height of fall of the raw material.
As the lift angle increases, the efficiency of the washing process increases as a result of better mixing and higher drop height of the raw material.

Preparation of agricultural products before processing or storage by washing is also an important procedure because of possible losses.

Finding a modern labile method is also a research task. Vegetable and fruit washing is carried out in different types of machines, the main purpose of which is to remove soil, sand, and other foreign elements.

When choosing the type of washing machine, one should take into account the type of raw material, the growing conditions, the type of soil, if it is a root crop, as well as the capacity of the line to ensure the quality of the product after washing.

The washing machines have the following requirements:

-A high degree of cleanliness of washed objects;

-Exclusion of spoilage of raw materials or broken and deformed containers;

-Minimum water and energy consumption;

-Ease of operation and maintenance;

-High operational reliability;

-Low overall dimensions and weight.

Machines for washing fruits, berries, and vegetables are divided into several types:

-Washing by bubbling;

-The raw material is completely immersed in the hopper with water, where the air is pumped through the holes in the tubes, resulting in a boiling water effect;

-Washing by dipping - in the receiving tub with water are installed scrapers moving elements that create the direction of movement of water and raw materials;

-Tumblast washing machines - raw materials are washed by water and the product is rubbed against the walls of the drum and the product parts themselves;

-Brush washing machines - the product is cleaned with brushes mounted on rollers.

These machines can be made in the following configurations - flat, drum, bowl type U.

\section{Research results and discussion.}


The two-drum root crop washing machine refers to equipment for the food industry, namely, devices for washing fruit and vegetable products, mainly with a solid structure. By the type of washing, the model refers to drum-type washing machines, where washing is carried out at the expense of friction between raw materials and the walls of the drum, in which washing is carried out.

The main technical specifications:

-Length of drums - $1250 \mathrm{~mm}$; diameters of drums in the form of truncated cones - large 90 and $75 \mathrm{~cm}$; small -60 and $54 \mathrm{~cm}$;

-The dimensions of the construction 1500x1200x1500mm;

-Productivity $1-3 \mathrm{tn} / \mathrm{h}$;

-The power consumption of electrical energy 2.2 $\mathrm{kW} / \mathrm{h}$;

-The engine speed of $1000 \mathrm{rpm}$;

-Water consumption at $0,3 \mathrm{MPa}, \mathrm{m}^{3} / \mathrm{h} 1.4$;

-Weight of construction - $150 \mathrm{~kg}$.

The constructed machine has smaller dimensions and accordingly weight and cost. It is clear that weight reduction is achieved due to the design of the drum with two cylindrical drums.

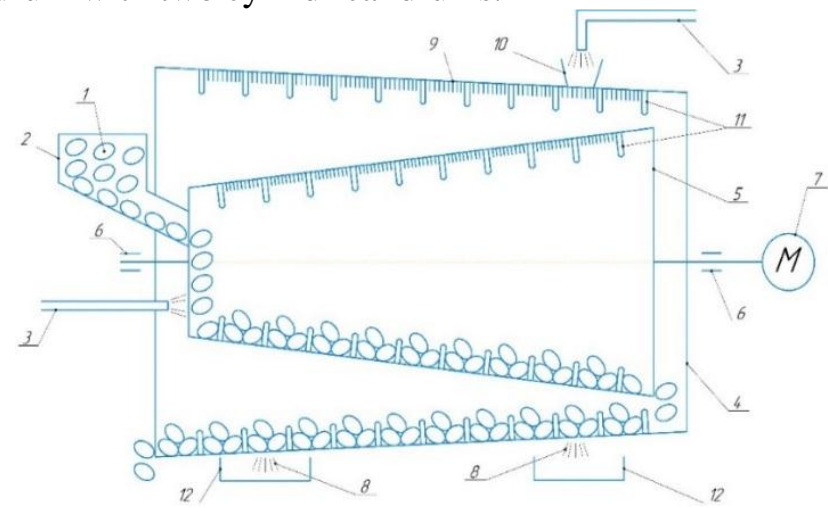

Fig.1.Schematic diagram of the Root Beet Washing Machine: 1-Root crops, 2 - hopper loading 3-water line, 4-internal cone drum, 5-internal cone drum, 6-support, 7- electric motor, 8drainage of dirty water, 9-brushes, 10-head of water intake, 11 spiral, 12-pallet

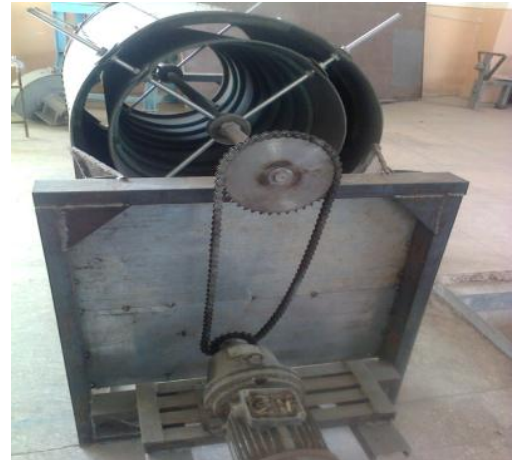

Fig.2. Scheme (left) and photo (photo) of the two-drum washer.

Washing quality with relatively equal size of the drum and the speed of moving the product through the drum of the washing machines is improved by increasing the path of the fruit in the process of washing. On the experimental base of Tashkent State Technical University with positive results were carried out technological tests of the twodrum washing machines of root crops of the proposed design.

As noted in the technical specifications of the studied washing machine, a three-phase $220 \mathrm{~V}$ electric motor with a turnover of the motor $1000 \mathrm{rpm}$.

Washing machines of drum type have optimum revolutions 0 from 10 to 20 revolutions per minute.

For the main reduction of the revolutions of the electric motor a gearbox reducing the revolutions by 30 times is used.

It was desirable to reduce the output torque of $35 \mathrm{rpm}$ to 14-16 rpm and therefore it was necessary to calculate the reduction by a chain drive.

In the drive of the washing machine, developed in the course project, the chain gear is used to reduce the frequency of rotation of the drive shaft.

The simplest and most common way is to use a driving roller single-row chain (PR), which was adopted for this study (figure below).

A simple chain transmission comes with two sprockets.

The main chain parameter is its pitch $t$, the other geometric parameters of the transmission are expressed as a function of the pitch:

Recommended optimum axle spacing;
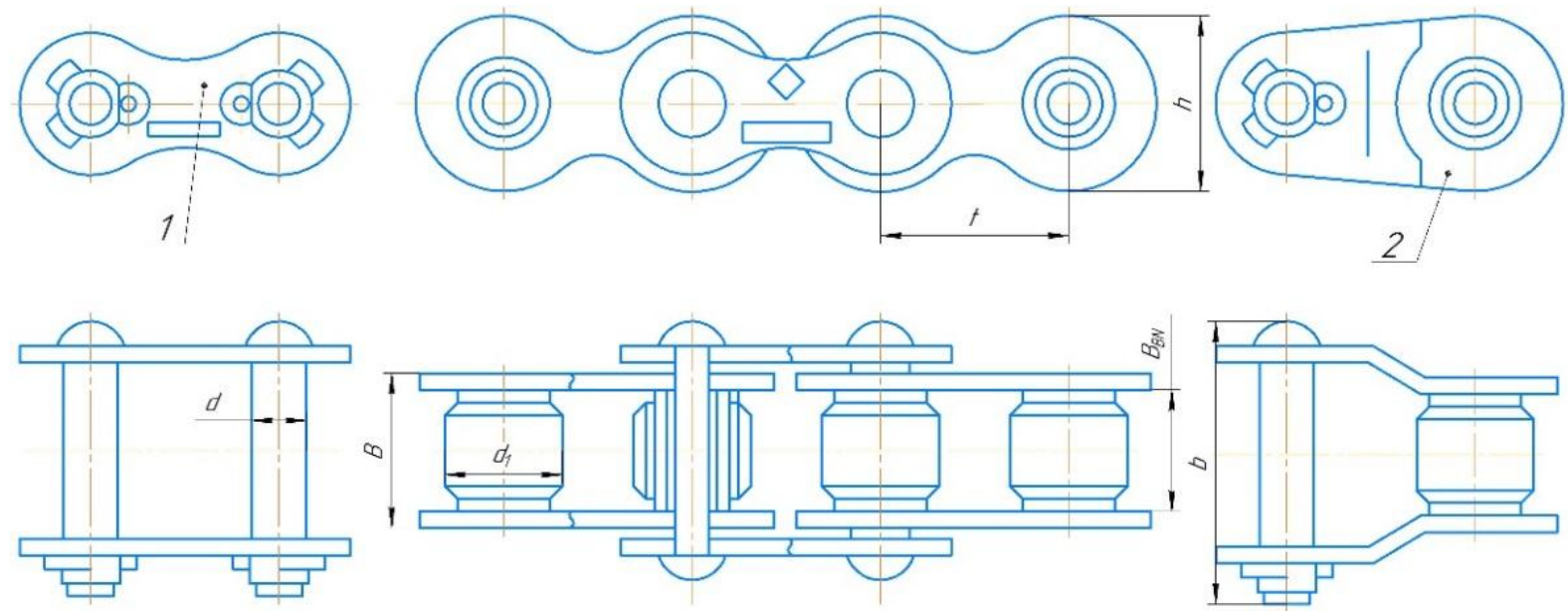

Fig.3. Single-row roller chain. 1 - connecting link; 2 - transition link. 
Pitch diameter of the sprocket:

$$
\mathrm{d}_{\mathrm{д}}=\frac{t}{\sin \frac{180^{\circ}}{z}}
$$

where $z$ - number of chainring teeth sprocket; $D_{e l}$ and $D_{e 2}$ - outside diameters of sprockets, defined according to GOST 592-81:

Let's take the initial data. Transmitted power $\mathrm{P}=2.2 \mathrm{~kW}$. Input sprocket speed $n_{1}=35 \mathrm{r} / \mathrm{min}$, output sprocket $n_{2}=$ $16 \mathrm{r} / \mathrm{min}$.

Angle between center lines and horizontal 450, periodical lubrication, one-shift operation.

We choose single-row roller chain (scheme, Fig. 2) from GOST [1] and determine the pitch by the formula (5):

$$
t=2,8 \sqrt[3]{\frac{T_{1} K_{\ni}}{\mathrm{z}_{1}[p] m}}
$$

Where $\mathrm{T}_{1}=\frac{P}{\omega_{1}}=\frac{30 P}{\pi n_{1}}=\frac{30 \cdot 2,2 \cdot 10^{3}}{3,14 \cdot 35}=660.5 \kappa$

$$
H \cdot M M \mathrm{~K}_{\ni}=1.625 \text {. }
$$

Number of teeth of the drive:

$$
\begin{gathered}
\mathrm{z}_{1}=31-2 \mathrm{u}=31-2 \frac{35}{16}=29 \\
\text { slave } \mathrm{z}_{2}=\mathrm{z}_{1} \mathrm{u}=25 \cdot 2,18=54
\end{gathered}
$$

The average value [p] is taken according to Table 7.18 from the reference book [1].

[p] $=20 \mathrm{MPa}$, number of chain rows $n=1$ :

$$
t=2,8 \sqrt[3]{\frac{660,5 \cdot 10^{3} \cdot 1,625}{29 \cdot 20 \cdot 1}}=30,4
$$

According to the table 7.15 [1] in accordance with GOST $13568-75$ we take the nearest big value $\mathrm{t}=31,75 \mathrm{~mm}$;

Let's define number of chain links $L_{t}$, preliminarily we find total number of teeth

$$
\mathrm{z}_{\mathrm{z}}=\mathrm{z}_{1}+\mathrm{z}_{2}=29+54=83
$$

$$
\begin{gathered}
\text { Correction } \mathrm{d}=\frac{z_{2}}{2 \pi} \frac{-z_{1}}{2 \cdot 3,14}=\frac{25}{2,0}=4,0 \\
\mathrm{a}=40 \mathrm{t} ; a_{\mathrm{t}}=\frac{a}{t}=40 .
\end{gathered}
$$

According to the formula:

$$
\mathrm{L}_{\mathrm{t}}=2 \mathrm{a}_{\mathrm{t}}+0,5 \mathrm{z}_{\mathrm{z}}+\frac{d^{2}}{a_{t}}=2 \cdot 40+0,5 \cdot 83+\frac{4^{2}}{40}=121,9
$$

Rounded to a whole number $L_{t}=122$.

Specify the interaxial distance using the formula $a=0,25 \mathrm{t}$

$$
\begin{gathered}
\left.\left[L_{t}-0,5 z_{z}+\sqrt{\left(L_{t}\right.}-0,5 z_{z}\right)^{2}-8 d^{2}\right]=0.2 \\
\cdot 30,4\left[122-0,5 \cdot 83+\sqrt{\left.(122-0,5 \cdot 83)^{2}-8 \cdot 4^{2}\right]}\right. \\
=1217 \text { MM }
\end{gathered}
$$

Determine the pitch diameters of the leading sprockets $[1,2]$

$$
\begin{gathered}
\mathrm{d}_{\text {д1 }}=\frac{t}{\sin \frac{180^{\circ}}{z}}=\frac{30,4}{\sin \frac{180}{29}}=284.11 \mathrm{MM} \\
\text { slave } \mathrm{d}_{\text {д2 }}=\frac{30,4}{\sin \frac{180^{\circ}}{54}}=533.3 \mathrm{MM}
\end{gathered}
$$

Outer diameters

$$
D_{e}=t\left(K_{z}+0.7\right)-0.31 d_{1}
$$

$$
\text { Where } \mathrm{K}_{\mathrm{z}}=\operatorname{ctg} \frac{180}{z} \text {; }
$$

$\mathrm{d}_{1}-$ roll diameter

$$
\begin{aligned}
& D_{\mathrm{e} 1}=30,4\left(\operatorname{ctg} \frac{180}{29}+0.7\right)-0.3 \cdot 19,05=320.1 \mathrm{~mm} \\
& D_{\mathrm{e} 2}=30,4\left(\operatorname{ctg} \frac{180}{54}+0.7\right)-0.3 \cdot 19,05=554.2 \mathrm{~mm}
\end{aligned}
$$

Table 1. Summary table of basic values

\begin{tabular}{|c|c|c|c|c|c|c|c|}
\hline $\begin{array}{c}K_{3} \text { correction } \\
\text { factor }\end{array}$ & $T_{l \text { axial load }}$ & $\begin{array}{c}z l \text { number of } \\
\text { teeth of the drive }\end{array}$ & $\begin{array}{c}z 2 \text { slave } \\
\text { number }\end{array}$ & $\begin{array}{c}T \text { chain } \\
\text { pitch }\end{array}$ & $\begin{array}{c}A \text { centre-to-centre } \\
\text { distance }\end{array}$ & $\begin{array}{c}d_{\partial l \text { sprocket }} \\
\text { diameter }\end{array}$ & $\begin{array}{c}d_{\partial 2} \text { sprocket } \\
\text { diameter }\end{array}$ \\
\hline 1.625 & $\begin{array}{c}660.5 \mathrm{~K} \\
H \cdot M M\end{array}$ & 29 & 54 & 31.75 & $1217 \mathrm{MM}$ & $284.11 \mathrm{MM}$ & $533.3 \mathrm{MM}$ \\
\hline
\end{tabular}

$\mathrm{C}$ is a coefficient that takes into account the conditions of installation and operation of the chain gear:

$$
K_{\ni}=K_{\Omega} K_{a} K_{H} K_{p} K_{c M} K_{n}
$$

Taking into account that the washing machine is working under quiet load we take $k l=1$, at center distance of less than $50 \mathrm{~cm} \quad k_{a}=1, k_{r}=1.25$ at manual chain adjustment, $k_{c m}=1.3$ at periodic lubrication, $k_{p}=1$ at single-shift operation, $k_{n}=1$ at chain slope up to 600 to horizon.

Total $K_{e}=1.25 \times 1.3=1.625$ 


\section{Conclusion}

Thus, the calculated chain transmission is used in a twodrum root crop washing machine, which has advantages over analogs $[3,4]$ :

- In addition, the efficiency of washing raw materials is increased by increasing the path of the fruit passing and, accordingly, increasing the time of contact interaction between the fruit and the washing elements;

- The designed machine has smaller dimensions and correspondingly lower weight and cost. (1500x1200x1500mm, $150 \mathrm{~kg}, 5$ million sum);

- The proposed machine can operate both independently and as part of a continuous mini processing line.

\section{References}

1. Course Design of Machine Parts. ed. Chernavsky S A, 2.eed.M.:Mashinostroenie.1987.-416s

2. General Technical Reference Guide, ed. Skorohodov E

A, 2.e ed. 1982.-415c.

3. www.besteq.ru

4. http://itsodessa.com/katalog_oborudovanija/oborudova nie_dlja_priemki_i_mojki_produkta

5. Application for the invention of a double drum root crop the washing machine. FAP 20140016 17.02.2014g. Norkulova K T, Umarov V F, Mamatkulov M M 